\title{
PROFILE: JUDITH WEIR
}

Judith Weir (b. 1954) studied composition with John Tavener (during schooldays), Robin Holloway (at Cambridge University) and Gunther Schuller (at Tanglewood). She first worked for Southern Arts as a composer in the community, and then spent some years in Scotland teaching at Glasgow University and RSAMD. During this time she began to write a series of operas, beginning with King Harald's Saga (for Jane Manning), The Black Spider and A Night at the Chinese Opera (both for Kent Opera). She recently succeeded Sir Peter

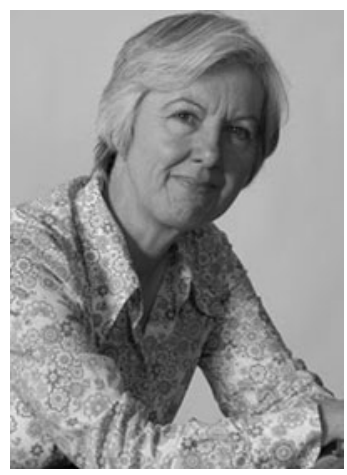
Maxwell Davies in the 388-year-old royal post of Master of The Queen's Music.

Q. What are you reading at the moment?

A. The Leonard Bernstein Letters. I didn't think I wanted to read them 'I'm not interested in conductors, or the glitzy side of music', I thought - but now I'm hooked. It covers a whole era of musicmaking; his correspondence style is as wildly expressive as his composing/conducting was. There are letters to him from just about everyone: Copland, Schuller, Messiaen, Feldman, Stockhausen. All the time he was conducting he thought he should really be composing; probably most of us composers have our own tiny version of that dilemma, juggling multifarious activities with the always too-small amount of 'pure time' available for composing.

Q. Which other artists have most influenced you?

A. When I began to be interested in new music as a teenager, the composer who most enthralled me was Cage - at first reading about him (in Ahead of the Game by Calvin Tomkins) rather than hearing him. What appealed initially was the crazy counter-intuition of his ideas; but I also responded to the I Ching and the sonic inventiveness of Sonatas and Interludes. Messiaen was the first 'modern composer' I would say I absorbed - all his work really, which at that time (late sixties/seventies) was still being written. Out of the post-war avant-garde, still in their heyday, I listened the most to Stockhausen and Berio. During my student days (1973-76), consciousness of the minimalists started to seep through; out of all the work applying to that description, nothing has ever thrilled me as much as the famous 1974 Steve Reich box set (of LPs, on DG, of Drumming).

After leaving university, I looked for models closer to my own age and situation who seemed to be working in ways I could try to emulate; names that come immediately to mind include Howard Skempton, Michael Finnissy and Edward McGuire. I have known my teacher Robin Holloway for a long time now, and I believe I've been influenced not so much by his music itself as by his ways of 
thinking. In later life, I’ve found deeper influence from outside music, and there is a constant stream of artists and other people whose work I admire and try to follow. A current example would be Ai Weiwei, and his practice of addressing huge political truths by means of extremely simple but also sophisticated concepts (allied with excellent craftsmanship, often involving large groups of people).

Q. What does collaboration mean to you?

A. A significant part of my work has been in opera and music theatre, genres which just have to involve the input of many other people. It very much depends which people - there are mostly pros about this meeting of minds and skills, but inevitably a few cons as well. However, my favourite aspect of collaboration is simply what takes place when a new piece is rehearsed by musicians for the first time. It seems to me that this is one of the most perfect give-and-take situations in existence. I'm talking here about working with small groups of musicians or singers, where extended conversation can freely take place in mid-rehearsal; it's fair to say the orchestral or operatic situation is not so good in this respect!

Q. How has your compositional process evolved over the years?

A. A very simple way to start would be to say it has relaxed. At a deep level, I know what I am looking for when I'm trying to articulate a concept and get started - which was always the scariest bit in earlier times. I can also say that I now know a lot more - about instruments, voices, professional situations, helpful examples from other art, and so on (though you can know too much - just occasionally raw ignorance can produce something wonderful!). So the crucial part of the process now is making the big artistic choices at the beginning; having made those choices (perhaps about the project itself, where it is, who it's for, and so on) I know much more about how I'll proceed and what will happen. In the last decade or so I've found myself sketching more, and throwing more away - I imagine this comes from increased confidence that better material will eventually appear. But I have to reiterate the cliché - that composing gets no easier, and quite possibly harder. Your standards have to be set higher (or there's no point in continuing) and self-criticism increases, for better and/or worse.

Q. What piece of art has most affected your own work?

A. I feel the biggest influences happen in earliest years, and therefore I have to give the accolade to Berio's Sinfonia which I got to know around 1970 as a very recent new work on a miraculously swift (for those days) record release conducted by the composer with the NY Phil and the Swingle Singers. In those early days it had only four movements, which is the way I still think of it! The aural beauty of the opening two movements, especially 'O King', was a stunning surprise in that era, yet the sound was still sophisticated and modern - I wouldn't have liked it otherwise. And the wit and skill of the Mahler collage, referencing contemporary politics and philosophy, amazes me still where did that idea spring from? I listened to everything in those days, but I'm not sure if I would have continued composing but for this miraculously-appearing, idiosyncratic object which I strove to emulate for several formative years. 